\title{
RETRACTED ARTICLE: Osteotomy in lateral position for correcting severe thoracolumbar kyphosis combined with hip flexion contracture in ankylosing spondylitis: a case report and literature review
}

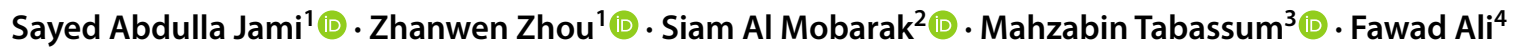

Received: 1 February 2020 / Revised: 24 June 2021 / Accepted: 25 June 2021 / Published online: 6 July 2021

(c) The Author(s), under exclusive licence to Springer-Verlag GmbH Germany, part of Springer Nature 2021

Jami, S.A., Zhou, Z., Mobarak, S.A. et al. Osteotomy in lateral position for correcting severe thoracolumbar kyphosis combined with hip flexion contracture in ankylosing spondylitis: a case report and literature review. Eur Spine J (2021). https://doi.org/10.1007/s00586-021-06913-1. The authors have retracted this article because its content substantially overlaps with an unpublished manuscript by a different author group. In addition, the authors did not obtain consent from the patient for the publication of the case and accompanying images; the scientific content of the article has therefore been removed to protect the patient's privacy. All authors agree to this retraction.

Sayed Abdulla Jami

jami41@live.com

Zhanwen Zhou

270632413@qq.com

Siam Al Mobarak

dr.siamalmobarak_cardio@hotmail.com

Mahzabin Tabassum

mahzabin.tabassum@hotmail.co.uk

Fawad Ali

Fawadchemist@gmail.com

1 Department of Spinal Surgery, General Hospital of Ningxia

Medical University, Ningxia Medical University, 804

Shengli Street, Xingqing District, Yinchuan 750004,

Ningxia, People's Republic of China

2 1St Affiliated Hospital of Guangxi Medical University,

Nanning 530021, Guangxi, People's Republic of China

3 Clinical Medicine, Xuzhou Medical University,

209 Tongshang Road, Xuzhou 221004, Jiangsu,

People's Republic of China

4 Department of Chemistry, Bacha Khan University,

Charsadda 24461, Pakistan 